\title{
A Comparative Study for Determining the Liquid Limit of Soils by Using the B.S. Cone Penetrometer and Casagrande Methods
}

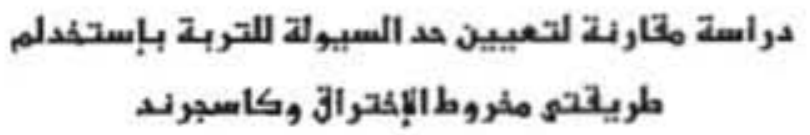

El-Metwally A. EI-Sekelly, Assistant Professor

Faculty of Engineering, Mansoura University

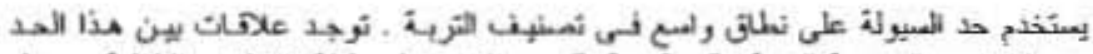

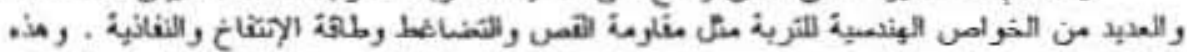

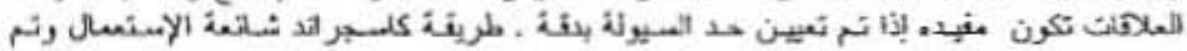

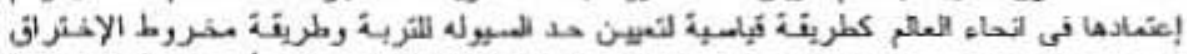

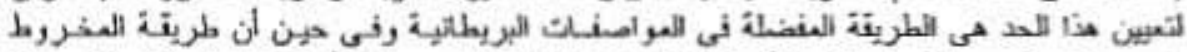

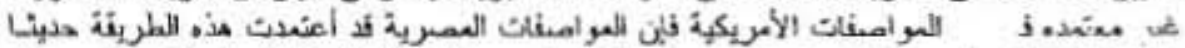

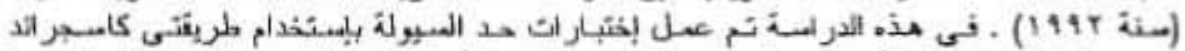

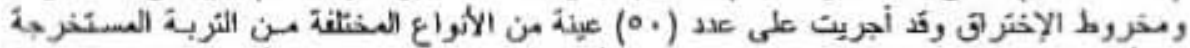

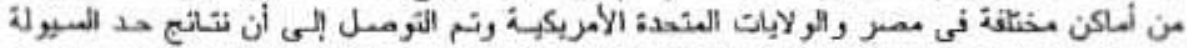

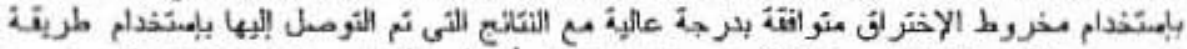

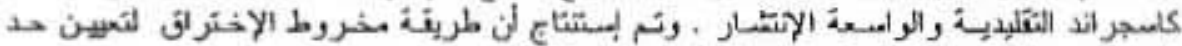

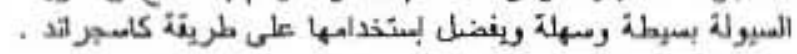

\section{ABSTRACT}

The liquid limit is widely used for the classification of soils. This limit has been correlated with many engineering properties of soils such as shear strength, consolidation, swelling potential, and perneability. These correlations could be rationalized if the liquid limit is accurately determined.

Casagrande method is commonly used and standardized worldwide for determining liquid limit of soils. The cone penetrometer is the British standard preferred method for determining this limit. The cone method has not been adopted yet by any of the American standards but it is recently adopted in the 
Egyptian code (1992). In this study, the liquid limit tests using the two methods were carried out on (50) soil samples of different types. The soiis were brought from different areas in Egypt and U.S.A. The results obtained from the B.S. cone penetrometer tests compared well with those obtained by the classic and most widely used Casagrande method. It was noted that the Correlation coefficient was verv high and a linear relationship was obtained. It is concluded that the B.S. cone penetroneter test is a simple and easy method for determining the liquid limit of a soil and it is preferred over Casagrande method.

\section{INTRODUCTION}

The liquid limit is widely used for the classification of soils. This limit has been correlated, empirically, with different engineering properties such as shear strength, consolidation, swelling potential, permeability, ect. (AASHTO T 258-81; Bowles, 1984; Carter and Bentley, 1991; Harison, 1988, Mulıunthan, 1991 and Chen, 1988). These correlations could be rationalized if the liquid limit is accurately determined.

Casagrande (1932) developed a method for liquid limit determination. This method is commonly used and standardized worldwide (e.g. AASHTO T 89-90; ASTM D 4318-84; B.S. 1377-1975 and the Egyptian code-1992). The cone penetrometer has been standardized by the British standards. Institution in B.S 1377-1975 and recently adopted by the Egyptian code (1992). However, the cone method has not been adopted yet in the American standards (ASTM and AASHTO).

In this study the results of the liquid limit tests obtained by cone penetrometer method was compared to those of the most widely used Casagrande method.

\section{REVIEW OF PREVIQUS WORK}

\section{Casagrande Method}

The liquid limit of a soil, determined according to this method, is the water content at which the two parts of a soil cake in the cup of the apparatus come into contact (flow) at the bottom of the groove along a distance of about $13 \mathrm{~mm}$, when the cup is dropped 25 blows from a height of $10 \mathrm{~mm}$ at the rate of two revolutions per second. 
Bowles (1984) pointed out that the Casagrande apparatus has some limitations that affect repeatability (single operator) and reproducibility (multi-laboratories) for the liquid linit. These limitations are -

1- Adjustment of liquid device to obtain $10 \mathrm{~mm}$ height of drop of the cup. Small deviations from $10 \mathrm{~mm}$ may affect the value of liquid limit as much as 10 points.

2. Controlling the quantity of soil in the cup of the device. AASHTO T89-90 recommended that sufficient quantity of soil cake shall be placed in the cup. The soil shall then be ieveled and at the same time trimmed to a depth of $10 \mathrm{~mm}$ at the point of maximum thickness (above the spot where the cup rests on the base).

3- The hardness of the rubber base, on which the cup impacts. In the B.S 1377-1975 a rubber base with specified hardness and resilience is recommended.

In addition to the above mentioned limitations it was observed that in using the manually operated Casagrande apparatus the rate of revolution (two revolutions per second) is difficult to be maintained and requires a well trained operator. This also affects the results significantly. One may overcome this problem by using a motonized apparatus while the inanually operated one is still in use in many laboratories.

In the B.S. 1377-1975 Casagrande method is the accepted procedure to determine the liquid limit of a soil providing that the device is correctly maintained and the test procedure is strictly adhered. But in this standard it is mentioned that "Experience has shown that it is difficult to maintain the apparatus in accordance with the standard and the results are subject to judgment of the operator".

\section{Cone penetrometer method}

This method is a British standard method for determining liquid limit of soils (B.S. 1377-1975). The penetrometer apparatus is the one used for deternining the penetration of bituminous materials, it is described in B.S. 4691-74; AASHTO T49-89 and ASTM DS-86. The apparatus was modified, at Mansoura University, by replacing the needle with a $31^{\circ}$ cone, the cone is made from machined stainless steel with smooth, potished surface. It has a length of 35 min and a mass of 33 gram, the total mass of the cone and its sliding shaft is $80 \mathrm{gm}$. Figure (1) shows the used apparatus. 
According to this method a metal cup Approximately $55 \mathrm{~mm}$ in diameter and $40 \mathrm{~mm}$ deep is filled with soil paste. The cone tip is lowered so that it just touches the soil surface. The cone shall then be released for a freefall into the soil for a period of 5 seconds, the apparatus is provided with an automatic controller, and thereafter the penetration depth is recorded. The liquid limit is defined as the moisture content vorresponding to a cone penetration of $20 \mathrm{~mm}$, therefore several trials, at least four, at different water contents on both sides of 20 mm penetration are used to construct a linear relationship plot between moisture content against the cone penetration

In the B.S. 1377, the cone penetrometer is preferred to the Casagrande apparatus as the cone method is simple and gives better repeatability and it is applicable to a wider range of Soils. "The cone peneirometer apparatus is easier to maintain in correct adjustment and the test procedure is less dependent on judgment of the operator".

Houlsby (1982) found that the surface rouglness of the cone significantly affects the liquid limit. He recommended that the cone surface should be smooth and it can be used either dry or lightly oiled before use.

\section{Experimentation}

In this investigation the manually operated Casagrande apparatus and the cone penetrometer which fitted with an automatic release and locking device were used in the liquid limit tests. The procedures followed were those given in B.S. 1377 (1975), AASHTO T 89-90 and ASTM D 4318-84.

The liquid limit tests were carried out on (50) soil saraples from different areas in Egypt and U.S.A (Dakahlia, Dimiatta, Port Saaid, Glaarbia, Sharkia, New Valley, Faioum, Beheera, Minia, Kafr El-Sheikh and Arizona). Furthermore, a wide range of soils, (e.g. silty clay, clayey sitt, loam, and sandy clay, ect.) has been used in the study. The soil samples were air dried and the tests were performed on the materials passing $0.425 \mathrm{~mm}$ (No. 40) sieve.

\section{Comparison between the two methods}

The test results obtained from the two methods were statistically correlated. The regression analysis was done by using a statistics package (STATGRAPHICS). This is shown in figure (2). 
The following relationship (linear model) was adopied -

$$
\text { L. } L_{c}=a_{0}+a_{1} \quad\left(L . L_{p}\right)
$$

- $L . L_{e}$ is the liquid limit obtained from Casagrande method.

- L. $L_{p}$ is the liquid limit obtained from cone penetrometer

$-a_{0}$ and $a_{\text {, }}$ are the model constants.

$$
\text { L. } \mathrm{L}_{\mathrm{c}}=0.75+0.987\left(\text { L. } \mathrm{L}_{\mathrm{p}}\right)
$$

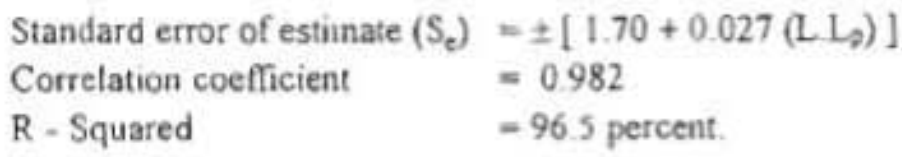

It was noted that correlation coefficient was very high for the linear correlation which indicated that the liquid limit results obtained from BS. cone penetrometer were comparabie to those obtained using the Casagrande method. In most cases the differences were slight, less than $3 \%$, and not significant if we consider the differences in repeatability and reproducibility of liquid limit values when determined using the Casagrande apparatus.

\section{Conclusions}

The liquid limit values obtained by using the B.S. cone compared well to those obtained by the classic and most widely used Casagrande method. There are insignificant differences between the results obtained using both methods. these deviations would be smaller than the normal variations likely to be obtained when using the Casagrande method.

The B.S. cone penetrometer test proved to be a simple and easy method for determining the liquid limit of a soil. Also the B.S. method is less dependent on the operator judgment. Therefore the B.S. cone penetrometer inethod would be preferred over the Casagrande one. 


\section{REFERENCES}

1- AASHTO Designation: T $89-90$ "Standard method of test for determining the liquid limit of soils" standard specifications for transportation materials and methods of sampling and testing. part II, 15 th edition, 1990.

2- AASHTO designation: T 258-81 (1990) "Standard method of test for determining expansive soils" standard specifications for transportation materials and methods of sampling and testing, part II, 15 th edition, 1990.

3- AASHTO designation. T49-89 " Standard method of test for penetration of bituminous materials" standard specifications for transportation materials and methods of sampling and testing, port II, 15 th edition, 1990.

4- ASTM D 4318-84 "Test method for liquid linit, plastic limit and plasticity index of soils". 1990 Annual book of ASTM standards, Volurne 4.08 , soil and Rock.

5. ASTM DS-86 "standard test method for penetration of bituminous materials" , 1988 Annual book of ASTM standards Volume 4.03. Road and Paving Materials.

6. Bowles, J.E, (1984) "Physical and Geotechnical properties of soils". 2nd McGraw-Hill Book Company, pp. 121-123.

7. BS 1377 (1975), "Methods of test for soils for civil engineering purposes" British Standard Institution, London.

8. B.S 4691: 1974 "Delermination of penetration of bituminous materials." British Standard Institution, London.

9. Carter, M and Bentley, S.P. (1991): "Correlations of soil properties" Pentch Press, London

10. Casagrande, A., (1932), Research on the Atterberg limits of soils, public roads Vol 13, No. 8, pp. 121-136.

11- Chen, F.H (1988): "Foundation on expansive soils" Elsevier publ. Co. New York.

12. Egyptian code for soil mechanics and foundation engineering (1992) "Laboratory tests" Part 2. Ministry of Housing and Reconstruction, Cairo. 
13- Harison, J.A (1988): "Using the BS cone penetrometer for the determination of the plastic limit of soils" Geoteclenique 38 No. 3 Dp. 433-438.

14- Houlsby, C.T (1982): "Theoretical analysis of the fall cone test" Geotechnique 32, No. 2 pp. $111-118$.

15- Muhunthan, B. (1991): "Liquid limit and surface area of clays" Geotechaique 41, No. I, pp 135-138.

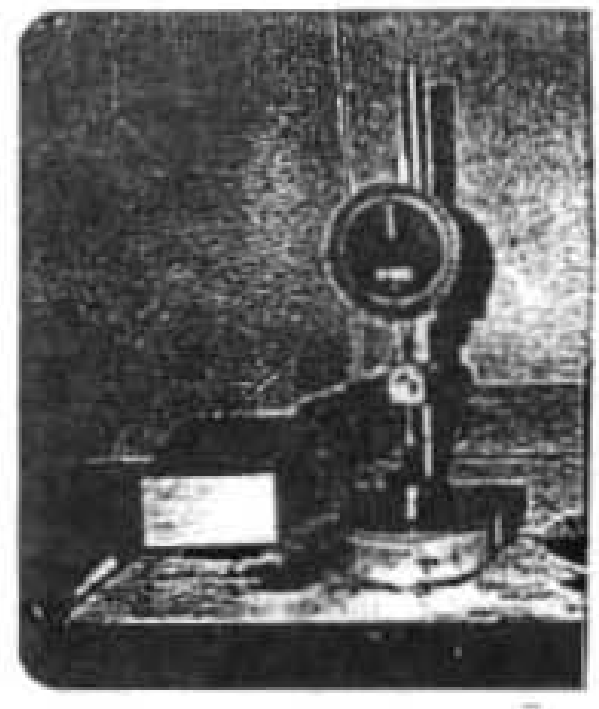

FIGURE (1): Cone penetrometer used for the determination of the liquid limit of soils. 


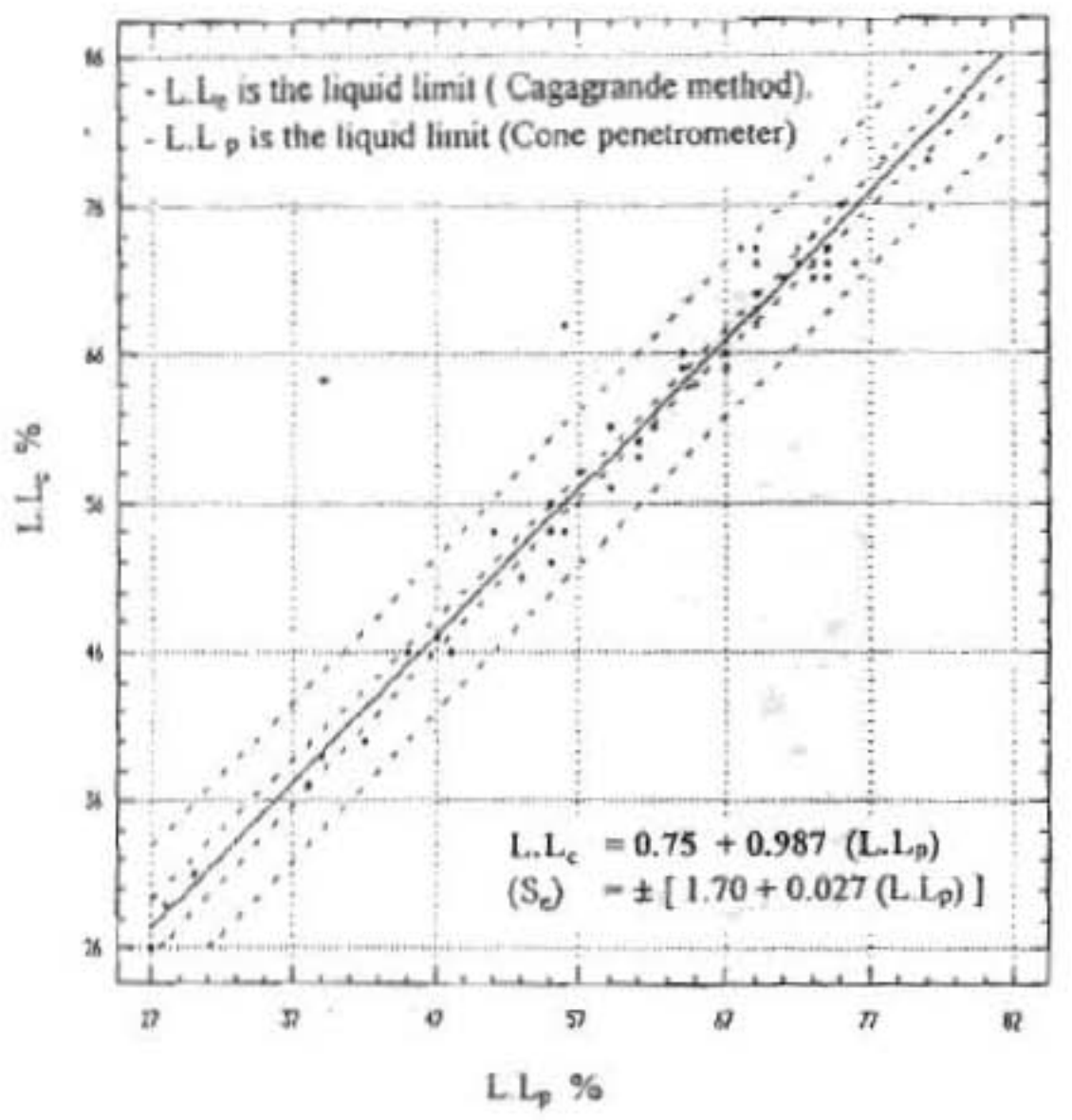

FIGURE (2): Correlation between liquid limit values obtained from Cosagrande and B.S. cone penetrometer methods. 